\title{
Inflammatory breast cancer: Still a diagnostic dilemma
}

\author{
W. M. Isichei, M. A. Misauno \\ Department of Surgery, Jos University Teaching Hospital Jos, Plateau state Nigeria \\ Email address: \\ mercyisichei@yahoo.com (W. M. Isichei); micoyedim@yahoo.co.uk (M. A. Misauno)
}

\section{To cite this article:}

W. M. Isichei, M. A. Misauno. Inflammatory Breast Cancer: Still a Diagnostic Dilemma. Journal of Surgery.

Vol. 2, No. 3, 2014, pp. 42-45. doi: 10.11648/j.js.20140203.12

\begin{abstract}
Background: Inflammatory breast cancer (IBC) is a rapidly progressive disease associated with high mortality in developing countries. The patients are managed for mastitis's first and IBC becomes a diagnosis of exclusion after failed response to appropriate antibiotic therapy. This study was aimed at evaluating the outcome of management of IBC in North central Nigeria. Patients and method: This was a prospective analysis of consecutive patients presenting with breast cancer at the Abubakar Tafawa Balewa University teaching hospital Bauchi (ATBUTH) from January 2011 to December 2012. Results: A total of 52 breast cancers were managed, mean age was 31+, 2years with an age range of $29-33$ years. There were 51 females and 1 male (f: $\mathrm{m}=51: 1)$. IBC accounted for $9(17.3 \%)$ of the breast cancers. Conclusion: IBC is frequently misdiagnosed as mastitis for various reasons and a high index of suspicion is required to clinch the diagnosis.
\end{abstract}

Keywords: Inflammatory, Breast, Cancer, Mastitis, Misdiagnosis

\section{Introduction}

Inflammatory breast cancer (IBC) is a rapidly progressive disease associated with a high mortality in developing countries. The disease is known to have a poor prognosis in the Africans, African Americans and persons of low socioeconomic status (1). When it affects older women, it is easier to diagnosis since the risk for breast cancer is known to increase in women above 40 years because there is a high index of suspicion by the attending physician. When it occurs in young women however, it can be challenging because mastitis is often associated with pregnancy and lactation therefore the first diagnosis is likely to be mastitis. IBC though associated with pregnancy and lactation, it is also a rare disease and many attending physicians are not likely to consider it as a first differential diagnosis. It is usually considered a differential diagnosis after failed response to conventional antibiotic treatment for mastitis. This initial misdiagnosis implies a delay in commencing treatment for IBC for weeks invariably leading to advanced disease at the time of diagnosis. The breast during pregnancy and lactation is prone to infections due to depressed immunity and there is also easy access to organisms from cracked nipples during the process of suckling which results in mastitis (2). Patients wit mastitis typically present with swelling in the affected breast, pain, peau d'orange, tenderness and fever. A finding of significant axillary lymph node enlargement should arouse a suspicion of IBC because this is not a common feature in mastitis. Laboratory and sonoragraphic findings for both diseases are indistinguishable. On the other hand, patients with IBC present with a short history of rapidly progressing generalized breast swelling associated with fever, tenderness with or without a discretely palpable lump and the presence of axillary Lymphadenopathy which maybe bilateral at the time of presentation(3).

The diagnosis of IBC when based on clinical acumen alone can be misleading because it is difficult to differentiate it from other inflammatory breast lesions at the early stages of the disease. This may be responsible for the late presentations commonly seen in our practice in addition to other factors.

Anyawu et al found lack of cancer awareness among patients and health workers in addition to poor diagnostic capability of the health institutions as significant factors responsible for the delay in diagnosis of breast cancer. These may be contributing factors to the many mistakes associated with diagnosing IBC (4). The patients are managed for mastitis's first and IBC becomes a diagnosis of exclusion after failed response to appropriate antibiotic therapy. There are no clear guidelines to assist the attending physician who has limited oncology training on how to diagnose IBC. There are limited radiologic investigations to aid the diagnosis of IBC such as CT scan and MRI although Alunni, J. P found the role of MRI to be debatable in diagnosing and monitoring treatment of 
patients with IBC and suggested it should be limited to selected patients (5-6). More definitive confirmation of IBC is by histopathologic examination and immunohistochemistry which are available in some referral centers may contribute to the diagnostic delay.

IBC has also been confused with other malignant breast lesions as seen in the report by Anne, $\mathrm{N}$ and Pallapothu, R. report of a Lymphoma of the breast presenting with erythema and edema mimicking inflammatory breast cancer(7). Alvarez et al also reported finding metastasis in the breast of patients that mimicked inflammatory breast cancer further buttressing the fact that IBC could be mistaken for other breast lesions(8)/*. Accurate diagnosis and prompt multimodal management with appropriate Neoadjuvant chemotherapy, surgery and radiotherapy is key to improved survival and reduction of the morbidity and mortality that are associated with this disease (9). Although IBC is rare, it has some geographical predisposition with a good number of cases reportedly found in Northern Africa (10). There is paucity of information on this disease in Nigeria where oncology services and research are limited(11). This study was aimed at evaluating the outcome of management of IBC in North central Nigeria.

\section{Patients and Methods}

This was a prospective analysis of consecutive patients presenting with breast cancer at the Abubakar Tafawa Balewa University teaching hospital Bauchi (ATBUTH) from January 2011 to December 2012. Consecutive patients who presented with breast disease at the surgical outpatient department were evaluated. Socio demographics, detailed history of disease progression was obtained, clinical examination, pathological diagnosis, chest x-ray, abdominal ultrasound, liver function, renal function and abdominal CT scan (for those who can afford it) were done. The subset of patients with inflammatory breast cancer were further isolated for this study. Non consenting Patients were excluded from the study. Data was extracted for socio demographics, presenting symptoms; clinical type of breast cancer, predisposing factors, duration of disease, initial management, histopatholoical type and stage of the disease. Data obtained was analyzed using excel version 6 and Epi info 7.

\section{Results}

A total of 52 breast cancers were managed. The patients mean age was $31+, 2$ years with an age range of $29-33$ years. There were 51 females and 1 male $(f: m=51: 1)$. The histopathologic types of the breast cancers were Invasive ductal carcinoma 37 (71.1\%), Inflammatory breast cancer 9 (17.3\%), medullary breast cancers $3(5.8 \%)$ while $3(5.8 \%)$ were phylloides tumors of the breast (Fig.1).

Inflammatory breast cancer was found to be bilateral in $3(27.3 \%)$ and unilateral in 6(66.7\%). There was significant weight loss in all patients, lactation in 5(55.6\%), pregnancy in $3(33.3 \%)$ while $1(11.2 \%)$ was found to be within the weaning period. All patients had Peau d'orange (Fig.1). Five patients $(55.6 \%)$ had bilateral axillary Lymphadenopathy and fever was found in $7(77.8 \%)$. The mean duration of disease prior to presentation at a health centre was 3 weeks with a range of $2-4$ weeks, mean time taken to obtain definitive diagnosis was 13 weeks with a range of 9-16weeks. All patients were initially treated for mastitis prior to diagnosis of IBC and all had T4d disease at the time of presentation to the tertiary institution.

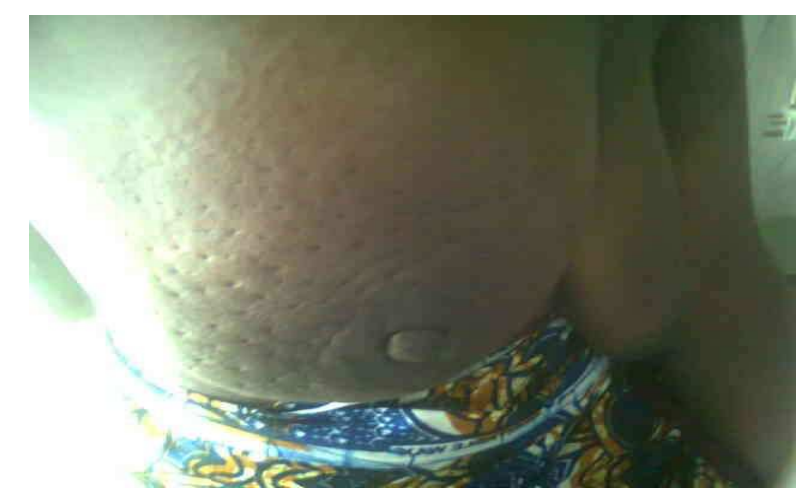

Fig 1. Inflammatory breast cancer in a 30years old woman manifesting with Peau d'orange.

\section{Discussion}

The main finding in this study was that all of the patients were initially misdiagnosed and treated for mastitis. This reflects the inadequacy of the mechanisms available in our system for diagnosis of IBC. The finding in our patients is much higher than the $50 \%$ misdiagnosis of IBC reported by Meyer (12). The reason for this disparity maybe due to lack of basic oncology training for the first attending physicians stationed at the district hospitals. The few doctors with some training in oncology are stationed at referral hospitals. In countries like Tunisia where IBC is endemic, the incidence of the disease has dropped from the initial 50\% to presently $10 \%$. This drastic fall in the disease incidence resulted from the use of more stringent criteria (Poussee Evolutive 3/T4d) for IBC diagnosis and an improvement in the socioeconomic level of Tunisia (10). IBC is an aggressive disease that equally requires an aggressive and precise multimodal approach that as not employed since the diagnosis of IBC in the was in these patients was at an advanced stage. Makower D and Sparano JA employed a multimodal approach of treating IBC using combined Neoadjuvant combination drug chemotherapy, surgery; radiotherapy and immunotherapy where indicated with success (12). Similar approach to management of IBC has been tried and reported have yielded positive results. Abrous-Anane, $\mathrm{S}$ had similar result from applying a multimodal treatment and reported that they achieved a better loco regional control with surgery in addition to Neoadjuvant chemotherapy than chemotherapy alone(14). The time between diagnosis and instituting response is of 
essence in treating IBC. The multifactorial delay results in advanced disease which is associated with a high mortality which will inevitably be the case in these study patients. This poor prognosis can be reduced by regular continuous medical education on IBC, its clinical presentation, management and how to distinguish the disease from other breast lesions especially mastitis. Shah and his colleagues developed and evaluated the usefulness or non usefulness of continuous medical education modules on breast cancer designed for primary care physicians. They found that physicians with the least understanding of breast cancer benefited the most .The module was adopted by Egypt and Tunisia with good results (15). We could try similar programs to help improve our breast cancer management outcomes.

The patients in this study were young and all were within the child bearing period. The disease in this group was either associated with pregnancy, lactation or weaning. These are common features found in women diagnosed wit IBC. Abdulraham et al reported similar findings that Breast cancer in Africans has generally been found to appear a decade earlier than in non Africans. There could be some genetic, environmental, dietary or socio cultural practices responsible for this predisposition in the Africans that are yet to be determined (15-16).

All patients in this study irrespective of age presented with stage 4 diseases within an average of 13 weeks from the time of first presentation). Breast cancer in young women all over the world follows an aggressive course made worse in this group of patients because of the type of cancer. Lo and colleagues carried out a comparative study to determine the difference between IBC in Egypt and IBC in United State. They reported that the significant difference between the two groups was in the disease progression. The Egyptian patients' had a more aggressive disease than the United States counter parts and further comparison analysis showed a distinct molecular phenotypes between the two groups(17). The findings in our study population connotes an aggressive disease. A less aggressive form of IBC in older women that was not associated with pregnancy or lactation and has a good prognosis been reported by Robertson et al where the patients are older and the history longer (18-19).

Recommendation:

There will be need for basic continuous medical education on cancer care for physicians and health workers. Conduct community based public awareness campaign on breast cancer to encourage early presentation for medical attention and to carry out multicentre study on IBC in our community.

\section{Conclusion}

Inflammatory breast cancer is frequently misdiagnosed as mastitis for various reasons and a high index of suspicion is required in clinching the diagnosis.

\section{References}

[1] Schlichting, J. A.;Soliman, A. S. ;Schairer, C.;Schottenfeld, D.;Merajver, S. Inflammatory and non-inflammatory breast cancer survival by socioeconomic position in the Surveillance, Epidemiology, and End Results database, 1990-2008.Department of Epidemiology, University of Michigan School of Public Health, 109 Observatory St., Ann Arbor, MI 48109-2029, USA. jschlic@umich.edu

[2] Waller KP. Mammary gland immunology around parturition. Influence of stress, nutrition and genetics. Adv Exp Med Biol. 2000;480:231-45.

[3] Tabbane F, el May A, Hachiche M, Bahi J, Jaziri M, Cammoun $\mathrm{M}$, et al. Breast cancer in women under 30 years of age. Breast Cancer Res Treat. 1985;6(2):137-44.

[4] Dahl beck SW, Donnelly JF, Theriault RL. Differentiating inflammatory breast cancer from acute mastitis. The Family physician 1995 Sep 1; 52(3):929-34. University of Minnesota Hospital and Clinic, Minneapolis, USA.

[5] Alunni JP. Imaging inflammatory breast cancer. Diagn Interv Imaging. 2012 Feb;93(2):95-103.

[6] Uematsu T. MRI findings of inflammatory breast cancer, locally advanced breast cancer, and acute mastitis: T2weighted images can increase the specificity of inflammatory breast cancer,2012 Oct;19(4):289-94. doi: 10.1007/s12282-012-0346-1. Epub 2012 Feb 21.Breast Imaging and Breast Intervention Section, Shizuoka Cancer Center Hospital, Naga-izumi, Shizuoka, 411-8777, Japan. t.uematsu@scchr.j

[7] Anne N, Pallapothu R. Lymphoma of the breast: a mimic of inflammatory breast cancer. World J Surg Oncol. 2011;9:125.

[8] Alvarez RH, Gong Y, Ueno NT, Alizadeh PA, Hortobagyi GN, Valero V. Metastasis in the breast mimicking inflammatory breast cancer. J Clin Oncol. 2012 Aug $1 ; 30(22): \mathrm{e} 202-6$.

[9] Li BD, Sicard MA, Ampil F, Abreo F, Lilien D, Chu QD, Burton GV. Trimodal therapy for inflammatory breast cancer: a surgeon's perspective 2010;79(1-2):3-12. doi: 10.1159/000318529. Epub 2010 Nov 3. Department of Surgery, Radiology, Pathology and Medicine, Louisiana State University Health Sciences Center in Shreveport, and Feist-Weiller Cancer Center, Shreveport, La 71130, USA. bli@1suhsc.edu

[10] Boussen H, Bouzaiene H, Ben Hassouna J, Dhiab T, Khomsi F, Benna F, et al. Inflammatory breast cancer in Tunisia: epidemiological and clinical trends. Cancer. 2010 Jun 1;116(11 Suppl):2730-5.

[11] Meyer KK. Diagnostic error in breast disease. Am Surg. 1975 Dec;41(12):774-85.

[12] Robertson FM, Bondy M, Yang W, Yamauchi H, Wiggins S, Kamrudin S, Krishnamurthy S, Le-Petross H, Bidaut L, Player AN, Barsky SH, Woodward WA, Buchholz T, Lucci A, Ueno NT, Cristofanilli M. Inflammatory breast cancer: the disease, the biology, the treatment. C A Cancer J Clin. 2010 Nov-Dec;60(6):351-75. doi: 10.3322/caac.20082. Epub 2010 Oct Department of Experimental Therapeutics, the University of Texas M. D. Anderson Cancer Center, Houston, TX, USA.CA Cancer J Clin. 2011 Mar-Apr; 61(2):134. Ueno, Naoto [corrected to Ueno, Naoto T]. 
[13] Abrous-Anane S, Savignoni A, Daveau C, Pierga JY, Gautier C, Reyal F, et al. [Management of inflammatory breast cancer after neo-adjuvant chemotherapy]. Cancer Radiother. 2011 Dec;15(8):654-62.

[14] Abdulrahman GO, Jr., Rahman GA. Epidemiology of breast cancer in europe and Africa. $J$ Cancer Epidemiol. 2012;2012:915610.

[15] Shah NM, Soliman AS, Benerjee M, Merajver SD, Ismail K, Seifeldin I, et al. Knowledge gained after a brief CME module on breast cancer diagnosis. J Cancer Educ. 2006 Fall; 21(3):169-74.

[16] Dauda AM, Misauno MA, Ojo EO. Histopathological types of breast cancer in Gombe, North Eastern Nigeria: a sevenyear review. Afr J Reprod Health. 2011 Mar; 15(1):109-11.
[17] Lo AC, Kleer CG, Banerjee M, Omar S, Khaled H, Eissa S, et al. Molecular epidemiologic features of inflammatory breast cancer: a comparison between Egyptian and US patients. Breast Cancer Res Treat. 2008 Nov;112(1):141-7.

[18] Lo AC, Kleer CG, Banerjee M, Omar S, Khaled H, Eissa S, et al. Molecular epidemiologic features of inflammatory breast cancer: a comparison between Egyptian and US patients. Breast Cancer Res Treat. 2008 Nov;112(1):141-7.

[19] Labidi SI, Mrad K, Mezlini A, Ouarda MA, Combes JD, Ben Abdallah $\mathrm{M}$, et al. Inflammatory breast cancer in Tunisia in the era of multimodality therapy. Ann Oncol. 2008 Mar;19(3):473-80. 